\title{
Teaching holistic nursing using clinical simulation: A pedagogical essay
}

\author{
Mary Ann Cordeau \\ Quinnipiac University, Hamden, USA \\ Correspondence: Mary Ann Cordeau. Address: Quinnipiac University, 275 Mount Carmel Avenue. Hamden, CT, 06510, \\ U.S.A. Email: mary.cordeau@quinnipiac.edu. \\ Received: July 30, 2012 \\ DOI : $10.5430 /$ jnep.v3n4p40 \\ Accepted: August 6, 2012 \\ URL: http://dx.doi.org/10.5430/jnep.v3n4p40 \\ Online Published: December 24, 2012
}

\section{Abstract}

Major nursing organizations that set standards for nursing practice and education emphasize the holistic nature of nursing practice. The patient-centered approach to holistic healing requires specialized knowledge, skills, and attitudes that move the student from focusing on the patient as an individual with physiological and/or psychological problems to a person on a healing journey. Strategies that foster the development of such knowledge, skills, and attitudes are necessary to prepare students to provide holistic care. Clinical simulation, an active teaching/learning strategy is effective for teaching holistic nursing practice. This pedagogical essay presents a holistic nursing clinical simulation scenario and grading rubric.

\section{Key words}

Holistic nursing, Clinical simulation, Active learning, Nursing education

\section{I ntroduction}

Holistic nursing practice focuses on patient-centered healing in which the nurse cares for the patient as a unified whole, recognizing that nursing care encompasses more than interventions necessary to influence and/or control physiological variables. Major nursing organizations that set standards for nursing practice and education emphasize the holistic nature of nursing practice. According to the American Nurses Association, "The nursing needs of human beings are identified from a holistic perspective and are met within the context of a culturally sensitive, caring interpersonal relationship" "[1]. An assumption of The American Association of Colleges of Nursing is that the "...baccalaureate generalist graduate is prepared to practice from a holistic, caring framework" ${ }^{[2]}$. The American Holistic Nurses Association defines holistic nursing as "all nursing practice that has healing the whole person as its goal" "3].

The patient-centered approach to holistic healing requires specialized knowledge, skills, and attitudes that move the student from focusing on the patient as an individual with physiological and/or psychological problems to a person on a healing journey. Strategies that foster the development of such knowledge, skills, and attitudes are necessary to prepare students to provide holistic care. Simulated clinical experience, an active teaching/learning strategy that mimics clinical experience, is being used in an American Holistic Nurses Association endorsed baccalaureate program to teach holistic patient-centered nursing care ${ }^{[4]}$. This pedagogical essay presents a method of using simulated clinical experiences to teach holistic patient-centered nursing care. 
Mannequins have successfully been used for teaching psychomotor skills to nursing students since the development of Mrs. Chase ${ }^{[5]}$. The development of moderate and high-fidelity mannequins that mimic human physiologic activity such as heart rate, blood pressure, respiratory rate, temperature and vocalization has made simulated clinical experiences possible. The assumption underlying simulated clinical experience is students learn better through hands on experience ${ }^{[6]}$. Depending on the scenario objectives, a moderate or high-fidelity mannequin can be programmed for changes in vital signs, heart, lung, and or bowel sounds and vocalizations during the student/mannequin interaction. Individuals who enact scripted scenarios known as standardized patients, are also used for simulated clinical experiences. Students have the opportunity to use cognitive, affective, and psychomotor skills when caring for a simulated patient. The kinaesthetic aspect of a simulated clinical promotes a change in attitudes and behaviors, important concepts for teaching healing principles ${ }^{[7]}$.

\section{Literature review}

In 1986, Whitmire and Utz noted "client simulations and demonstration and practice of holistic nursing interventions" were helpful for teaching holistic nursing ${ }^{[8]}$. Although Whitimier and Utz ${ }^{[8]}$ noted the effectiveness of simulation for teaching holistic nursing, little has been written on this topic since that time. No research on teaching holistic nursing using simulated clinical experience was found however, several related studies which focus on simulation as active learning were identified. Blum, Hickman, Parcells and Locsin ${ }^{[9]}$ determined that simulation technology had value for teaching caring behaviors to RN-BSN students. Hoke and Robbins ${ }^{[10]}$ studied the effect of active learning on clinical success. They reported an increase in both the didactic course and clinical grades following active learning activities ${ }^{[10]}$. Adler ${ }^{[11]}$ found that students who participated in a massage workshop developed better assessment skills and an increase in comfort level in interacting with the geriatric residents at the facility. A review of published simulated clinical scenarios revealed the majority of scenarios focus on care of a patient with a physiologic problem ${ }^{[12,13]}$. A limited number of scenarios that focused on care of a patient with a psychological disorder such as paranoid schizophrenia ${ }^{[12]}$ and mood disorder ${ }^{[14]}$ were identified.

\section{Holistic patient-centered nursing care}

The holistic nurse provides "patient-centered care" ${ }^{[15]}$ using the "holistic nursing practice process" ${ }^{[15]}$. The holistic nursing practice process is equivalent to the Nursing Process. The American Holistic Nurses Association defines holistic nurse as:

A nurse who recognizes and integrates body-mind-emotion-spirit-environment principles and modalities in daily life and clinical practice, creates a caring healing space within herself or himself that allows the nurse to be an instrument of healing, shares authenticity of unconditional presence that helps to remove the barriers to the healing process, facilitates another person's growth (body-mind-emotion-spirit-energetic-environment conditions), and assists with recovery from illness or transition to a peaceful death ${ }^{[15]}$.

The definition of healing used in the BSN program is drawn from the Scope and Standards of Holistic Nursing Practice ${ }^{[15]}$. According to Mariano, "Healing involves those physical, mental, social, and spiritual processes of recovery, repair, renewal, and transformation that increase wholeness and often (though not invariably) order and coherence" ${ }^{\text {[15] }}$. Healing is a journey of integration and harmony within the self and the world. The holistic nurse is viewed as an instrument of healing. The holistic nurse understands the complex nature of human beings and promotes and supports the integration of the healing processes in the self and others. The healing processes are introduced in the fall semester junior year and are built upon during the remainder of the program ${ }^{[16]}$.

Within the holistic framework, patient-centered care respects and responds to “...patient preferences, [holistic] needs, and values...” To provide patient-centered care, the holistic nurse uses the holistic nursing process to meet client needs. In the 
BSN program client needs are identified within a framework that has nine holistic variables. The framework was adapted from Mariano's ${ }^{[15]}$ definition of healing and the Integrative Health and Wellness Assessment (Dossey, Luck, Schaub, \& Keegan) ${ }^{[17]}$. They are physiologic variables, psychological variables, spiritual variables, relationship variables, cultural variables, economic variables, environmental variables, life balance variables, and health management variables.

\section{Simulated clinical experience}

The Nursing Education Simulation Framework ${ }^{[18]}$ is used to guide the simulated clinical experiences at the University. All simulated clinical experiences are operated using the on the fly method in which the facilitator responds to the student's use of the holistic caring process in real time. This increases the fidelity of the experience. Simulated clinical experiences include a prebriefing, clinical scenario, simulation experience, and debriefing ${ }^{[19]}$. The entire time for this scenario is 40 minutes (see Table 1).

Table 1. Time line for simulated clinical experience

\begin{tabular}{|c|c|c|c|}
\hline Event & Time of Occurrence & $\begin{array}{l}\text { Length of } \\
\text { Event Time }\end{array}$ & Description of activity \\
\hline $\begin{array}{l}\text { Prebriefing } \\
\text { Class Orientation }\end{array}$ & Beginning of semester & 30 minutes & $\begin{array}{l}\text { Orientation video of clinical simulation experience (10 } \\
\text { minutes) } \\
\text { Description of scenario } \\
\text { Scenario is posted on Black Board at this time NOTE: } \\
\text { This activity is only necessary for first time simulation } \\
\text { users }\end{array}$ \\
\hline $\begin{array}{l}\text { Prebriefing } \\
\text { Small Group } \\
\text { Orientation } \\
\text { 5-6 students }\end{array}$ & $\begin{array}{l}\text { Individualized, based on } \\
\text { student schedule, it should } \\
\text { occur close to scheduled } \\
\text { simulated clinical experience }\end{array}$ & 20 minutes & $\begin{array}{l}\text { Students have hands on experience, learn to take } \\
\text { mannequin vital signs, familiarize self in environment } \\
\text { NOTE: This activity is only necessary for first time } \\
\text { simulation users }\end{array}$ \\
\hline $\begin{array}{l}\text { Simulated Clinical } \\
\text { Experience: } \\
\text { Pre-simulation } \\
\text { Knowledge } \\
\text { Assessment }\end{array}$ & $\begin{array}{l}7 \text { minutes prior to } \\
\text { student/mannequin/ } \\
\text { Standardized patient } \\
\text { interaction }\end{array}$ & 5 minutes & $\begin{array}{l}\text { Knowledge is assessed by asking student(s) basic } \\
\text { questions. Questions vary from student to student. } \\
\text { Sample questions: } \\
\text { What are some safety concerns you have in caring for } \\
\text { Mrs. Weeks? } \\
\text { Why is Mrs. Weeks taking aspirin? } \\
\text { What is an ischemic stroke? }\end{array}$ \\
\hline $\begin{array}{l}\text { Simulated Clinical } \\
\text { Experience: } \\
\text { Report }\end{array}$ & $\begin{array}{l}2 \text { minutes prior to } \\
\text { student/mannequin/ } \\
\text { standardized patient interaction }\end{array}$ & 2 minutes & $\begin{array}{l}\text { Facilitator plays nurse role and gives student end of shift } \\
\text { report. The report is used to set the stage for the } \\
\text { particular sub-scenario. The sub-scenario information } \\
\text { can be used. Once student(s) are ready, the facilitator } \\
\text { enters the control room and begins the scenario. }\end{array}$ \\
\hline $\begin{array}{l}\text { Simulated Clinical } \\
\text { Experience: } \\
\text { student/mannequin/ } \\
\text { standardized patient } \\
\text { interaction }\end{array}$ & $\begin{array}{l}\text { Occurs after successful } \\
\text { knowledge assessment }\end{array}$ & $15-20$ minutes & $\begin{array}{l}\text { The student knocks on the patient room door to signal the } \\
\text { start of the scenario. When using a mannequin, the } \\
\text { "patient” (mannequin) instructs the student to enter and } \\
\text { the scenario begins. When using a standardized patient } \\
\text { the standardized patient instructs the student to enter. } \\
\text { This is the time when the student(s) use the holistic } \\
\text { caring process. This experience is video recorded }\end{array}$ \\
\hline Debriefing & $\begin{array}{l}\text { Occurs after the } \\
\text { student/mannequin/ } \\
\text { standardized patient interaction }\end{array}$ & $\begin{array}{l}15-20 \text { minutes or } \\
\text { longer depending } \\
\text { on student(s) } \\
\text { learning needs }\end{array}$ & $\begin{array}{l}\text { The student(s) facilitator/instructor watch and critique } \\
\text { the performance. }\end{array}$ \\
\hline
\end{tabular}

A main scenario focusing holistic nursing practice with specific learning outcomes was developed for the experience (see Table 2). 
Table 2. Clinical simulation scenario: holistic care of a client with ischemic stroke

\section{Expected Simulation Run Time: 20 minutes Guided Reflection Time: 20 minutes}

\section{Client Need Categories:}

Safe and Effective Care Environment: Safety and Infection Control

Psychosocial Integrity: Therapeutic Communication and Environment

Physiological Integrity: Basic Care and Comfort

Physiological Integrity: Pharmacological Therapy

Physiological Integrity: Reduction of Risk Potential

Physiological Integrity: Illness Management

\section{Caring Process Learning Outcomes:}

Identify one physiological caring need

Identify one psychological, spiritual, environmental, relationship, cultural, life balance, economic or health management caring need Implement holistic nursing interventions to meet identified caring needs

Provide patient-centered care

Implement critical thinking when assessing vital signs in relation to medication administration

Evaluate care provided

Setting: Rehabilitation Unit of a Long Term Care facility

Time: 8:00 AM

Name: Clara Weeks ID Number: 1234

Date of Birth: 8/30/1940

Gender: F Age: 70

Race: Caucasian

Weight: 145 lbs Height: 5’2”

Religion: Catholic

Major Support: Husband

Phone: 203-585-0234

Allergies: None

Attending Physician/Team: Dr. J. O’Donnell

Past Medical History:

Hypertension, smoked 1 pack per day for 40 years, has not smoked in 10 years. Mrs. Weeks stated she did not always remember to take her medications as prescribed.

\section{History of Present Illness:}

Mrs. Weeks was admitted to your unit 1 week ago. She is recovering from an Ischemic Stroke, (CVA). She has right sided hemiparesis. She is receiving physical therapy and occupational therapy. 
Table 2. (continued)

\section{Medications taken at home: \\ Lopressor 50 mg, every day \\ Lipitor $40 \mathrm{mg}$, every day \\ Social History:}

Mrs. Weeks is a retired schoolteacher who lives with her husband in a single story home. She attends church services weekly and is a volunteer religious education instructor. She and her husband eat lunch at the senior center two times per week. Her husband has hypertension. She enjoys cooking, reading, quilting, and gardening. She walks 2 miles outdoors or on a treadmill five times per week. Mrs. And Mr. Weeks have a daughter and two grandchildren. She has a cat named Sunshine.

\section{Psychomotor Skills required prior to simulation:}

Vital sign assessment

Medication administration

\section{Cognitive Skills required prior to simulation:}

Knowledge of the holistic caring process (class instruction and assigned reading)

Knowledge of illness management of a client with ischemic stroke/impaired mobility (independent reading)

Knowledge of illness management of a client with hypertension (independent reading)

Knowledge of vital sign values related to medication administration (independent reading, drug guide)

Therapeutic Communication skills (view communication video, pre-hospital skills lab)

Knowledge of client teaching (class instruction and assigned reading)

\section{Assignment:}

You are assigned to administer 8 AM medications to Mrs. Weeks

You can be assigned to administer any or all of the following medications:

You can be assigned to provide client teaching for any or all of the following medications:

Lopressor, 100 mg every day in divided doses

- Hold for Systolic BP < 110 and Diastolic < 64, Hold for Pulse $<60$

- $\quad$ Colace $50 \mathrm{mg}$ every day at bedtime

- Aspirin $81 \mathrm{mg}$ every day

- $\quad$ Lipitor 40 mg every day

Other:

You are expected to arrive in full uniform 5 minutes prior to the start of your scenario.

You must bring your stethoscope and wear a watch with a second hand.

Sub scenarios focusing on one holistic principle related to the main scenario was developed (see Table 3). This scenario was developed over five years based on faculty observation and student evaluations of the experience. 
Table 3. Holistic patient-centered care sub-scenarios

\section{Sub-scenario 1- Holistic patient-centered care of a patient with physiological needs and Critical Thinking}

Dosage of Lopressor to high for patient. Clara is experiencing hypotension.

Mannequin Settings: BP 102/64, Pulse 62

\section{Possible prompts or facilitator statements:}

No verbal cues or condition statements given to student.

"I feel so lightheaded during Physical Therapy, but I am afraid to tell the therapist because I know I need the therapy to get better and go home."

"I feel so lightheaded when I get out of bed, sometimes I need to hold on to the bedside table."

"I feel so lightheaded when I get up from my chair, yesterday afternoon I had to sit back down until my husband came to visit me."

"I feel so tired in the afternoon, I take a nap, I don't know I how I will be able to cook supper at home."

\section{Sub-scenario 2 Holistic patient-centered care of a patient with physiological needs - Critical Thinking - Lopressor}

\section{Administration}

Dosage of Lopressor to high for patient. Clara is experiencing bradycardia

Mannequin Settings: BP 112/68, Pulse 58 She states:

\section{Possible prompts or facilitator statements:}

No verbal cues or condition statements given to student

"I feel so lightheaded during Physical Therapy, but I am afraid to tell the therapist because I know I need the therapy to get better and go home."

"I feel so lightheaded when I get out of bed, sometimes I need to hold on to the bedside table."

"I feel so lightheaded when I get up from my chair, yesterday afternoon I had to sit back down until my husband came to visit me."

"I feel so tired in the afternoon, I take a nap, I don't know I how I will be able to cook supper at home."

\section{Sub-scenario 3 Holistic patient-centered care of a patient with socio-cultural needs}

Clara is worried about her husband who is caring for himself at home. Specifically, Clara is worried about her husband's diet. He has hyperlipidemia and needs to be on a low fat diet. Clara has done the majority of the grocery shopping and cooking for the family. She is worried that her husband is not following his low fat diet and will develop "heart problems"

\section{Facilitator Statement:}

"I have not slept all-night; I am so worried about my husband." "My husband has not been on his low fat diet since I had my stroke"

\section{Sub-scenario 4 Holistic patient-centered care of a patient with psychological needs}

Clara is worried because her husband informed her that her cat Sunshine is not eating. She feels a loss of control over the situation and feels guilty that her perceived lack of self-care led to her stroke. She feels that Sunshine misses her and that is the reason he is not eating. She is expressing a desire to leave the rehabilitation center earlier than planned.

\section{Facilitator Statement:}

"If I took better care of myself I would not have had this stroke and I would be home with Sunshine. Only I know how to care for him, I know just what he likes to eat. He misses me and will not eat because he is sad." 
Table 3. (continued)

\section{Sub-scenario 5 Holistic patient-centered care of a patient with psychological needs}

Clara is anxious because she does not think the strength on her right side is returning fast enough.

\section{Facilitator Statement:}

"I don't understand why I am not stronger by now. In the hospital they told me I would be all better very soon. I have been here one week and I don't seem much stronger." Maybe this is it for me; I will not get any better."

Sub-scenario 6 Holistic patient-centered care of a patient with spiritual needs

Clara feels that her stroke is the result of divine punishment. She feels a spiritual void in her life.

\section{Facilitator Statement:}

"I don't know why I am being punished with this stroke." "I go to church, try to help my neighbors, and say my Rosary. I wonder if God cares about me or listens to my prayers.”

\section{Sub-scenario 7 Holistic patient-centered care of a patient with cultural needs}

Clara has concerns over her ability to resume her roles as a wife, mother, grandmother and homemaker.

\section{Facilitator Statement:}

"I am so worried about going home and caring for my husband and home. I get so tired in the afternoon, I need to take a nap, how will I get my work done at home if I am sleeping all day?" "What will my husband think about me if I am not able to do take care of everything?"

\section{Sub-scenario 8 Holistic patient-centered care of a patient with environmental needs}

Clara is frustrated because she feels her room in the long term care facility is not comforting. She misses the morning sunshine because her blinds are drawn. She misses her home and she feels the staff in facility are not careful with her things.

\section{Facilitator Statement:}

"It is so dark in here; I miss the fresh air and sunshine. Where are my rosary beads? It seems like someone is always putting them where I can't find them, yesterday when I returned from PT, I found them on the floor. I really want to leave this place."

\section{Sub-scenario 9 Holistic patient-centered care of a patient with health management needs}

Clara is worried that she will forget to take her medications at home and will have another stroke.

\section{Facilitator Statement:}

“My doctor told me I am going to have to take an aspirin every day. I couldn't always remember to take my pills before, I hope I don't have another stroke because I forgot to take my pills."

\section{Sub-scenario 10 Holistic patient-centered care of a patient with health management needs}

Clara has a knowledge deficit related to taking aspirin

\section{Facilitator Statement(s):}

“Usually when I take aspirin I have some kind of pain. Why do I have to take aspirin when I don't have any pain?

"I heard that aspirin causes "bleeding” and I am very concerned about this."

“Now that I take a low dose aspirin every day, I will take Excedrin not aspirin when my arthritis acts up” 
Table 3. (continued)

Sub-scenario 11 Holistic patient-centered care of a patient with health management needs

Clara has a knowledge deficit related to taking Lopressor

Facilitator Statement(s):

"The nurse told me I need to check my heart rate when I am on Lopressor why do I need to do that?"

"Can you show me how to take my pulse?”

"Lately, my mouth is so dry; I think they put too much salt in my food."

Sub-scenario 12 Holistic patient-centered care of a patient with health management needs

Clara has a knowledge deficit related to taking Lipitor

Facilitator Statement(s):

"I know that I must take my Lipitor before bed but sometimes I am so tired that I forget so I take two the next night."

"Sometimes I enjoy a small glass of grapefruit juice in the morning but my friend Martha told me that I am not supposed to have grapefruit juice when I am taking Lipitor.”

"I was so happy when my physician put me on Lipitor, once my cholesterol level became normal I was able to eat my favorite foods such as sausage, cheese and regular ice cream I don't like that low fat ice cream."

\section{Sub-scenario 13 Holistic patient-centered care of a patient with economic needs}

Clara is on medicare and is worried that her medicare coverage will not be enough to cover the cost of her care in the rehabilitation center.

\section{Facilitator Statement:}

"I need to get out of this place soon, if I don't all of our life savings will be gone."

Sub-scenario 14 Holistic patient-centered care of a patient with relationship needs

"I have always been the caregiver in my family I took care of my mother and mother-in-law, I don't like relying on my husband and daughter. I feel like such a burden to my family.”

Sub-scenario 15 Holistic patient-centered care of a patient with life balance needs

Clara is worried about how she will have the time to do her daily physical therapy with all of her homemaking duties.

\section{Facilitator Statement:}

"I don't know how I am going to manage going to PT three times a week and do my exercises at home with everything else I need to do at home. Maybe I will give up going to PT and just do my exercises at home.”

Students use the Simulation Design Scale ${ }^{[18]}$ to evaluate their simulation experiences. The use of a main scenario with sub scenarios permits flexibility in implementing the scenarios with the students and increases fidelity. Students have knowledge of the overall scenario but do not know what exactly to expect during the simulation experience. This mimics the experience of the student's preclinical knowledge of a patient's medical history and nursing assessment but no experience with what to expect when they initially meet the patient. The experience can be conducted individually or in small groups. Formative and Summative evaluations can be used with the scenarios. One on one student/facilitator simulations are conducted at the University. The facilitator is a faculty member who conducts the scenario and debriefing. The clinical simulation process used at this University has been previously published ${ }^{[20]}$. Student success in meeting scenario objectives is measured by a grading rubric (see Table 4). 
Table 4. Holistic patient-centered care assessment rubric

Pass Needs Improvement

Pre-simulation knowledge assessment Pass Needs review

Y (Yes) N (No) P (Prompting) NI (Needs Improvement) N/A (Not Applicable)

\begin{tabular}{|c|c|c|c|c|c|c|}
\hline Intervention & Yes & No & $\mathbf{P}$ & N/I & N/A & Comments \\
\hline $\begin{array}{l}\text { Safety Infection Control } \\
\text { Checked name band } \\
\text { Washed hands } \\
\text { Asked pt. how she felt } \\
\text { Read nursing note } \\
\text { Applied gloves } \\
\text { Bed in lowest position } \\
\text { Bedside table near pt. } \\
\text { Belongings on table } \\
\text { Call bell in reach }\end{array}$ & $\mathbf{X}$ & $\mathbf{X}$ & $\mathbf{X}$ & $\mathbf{X}$ & $\mathbf{X}$ & XXXXXXXXXXXXXXXXXX \\
\hline $\begin{array}{l}\text { Therapeutic Communication } \\
\text { Broad opening statements } \\
\text { General Leads } \\
\text { Reflection } \\
\text { Pause/Silence } \\
\text { Listened to pt. } \\
\text { Acknowledged pt. feelings } \\
\text { Assessed and stated observations } \\
\text { Provided information } \\
\text { Validated pt. understanding } \\
\text { Complied with pt. desires }\end{array}$ & $\mathbf{X}$ & $\mathbf{X}$ & $\mathbf{X}$ & $\mathbf{X}$ & $\mathbf{X}$ & XXXXXXXXXXXXXXXXXX \\
\hline $\begin{array}{l}\text { Basic Care and Comfort } \\
\text { Inquired of patient's wellbeing } \\
\text { Left cane near patient }\end{array}$ & $\mathbf{X X}$ & $\mathbf{X}$ & $\mathbf{X}$ & $\mathbf{X}$ & $\mathbf{X}$ & XXXXXXXXXXXXXXXX \\
\hline $\begin{array}{l}\text { Critical thinking } \\
\text { Assessed BP / BG } \\
\text { Administered medications based } \\
\text { on assessment }\end{array}$ & $\mathbf{X X}$ & $\mathbf{X}$ & $\mathbf{X}$ & $\mathbf{X}$ & $\mathbf{X}$ & XXXXXXXXXXXXXXXXXX \\
\hline $\begin{array}{l}\text { Pharmacological } \\
\text { Therapy/Reduction of Risk } \\
\text { potential } \\
\text { Right drug } \\
\text { Right client (state name) } \\
\text { Right route } \\
\text { Right time } \\
\text { Right dose } \\
\text { Right documentation }\end{array}$ & $\mathbf{X X}$ & $\mathbf{X}$ & $\mathbf{X}$ & $\mathbf{X}$ & $\mathbf{X}$ & XXXXXXXXXXXXXXXXXX \\
\hline $\begin{array}{l}\text { Illness Management } \\
\text { Assessed knowledge deficits } \\
\text { Provided accurate information } \\
\text { Assessed client knowledge post } \\
\text { teaching }\end{array}$ & $\mathbf{X X}$ & $\mathbf{X}$ & $\mathbf{X}$ & $\mathbf{X}$ & $\mathbf{X}$ & XXXXXXXXXXXXXXXXXX \\
\hline $\begin{array}{l}\text { Self-Evaluate care } \\
\text { Used critical thinking during } \\
\text { debriefing }\end{array}$ & $\mathbf{X X}$ & $\mathbf{X}$ & $\mathbf{X}$ & $\mathbf{X}$ & $\mathbf{X}$ & XXXXXXXXXXXXXXXXXX \\
\hline
\end{tabular}




\section{Simulated clinical experience and teaching holistic patient- centered care}

Simulated clinical experience is useful for teaching holistic variables. Most students do not have difficulty identifying the physiological variables. They express excitement at implementing skills to meet physiologic needs and concern related to meeting nonphysical needs. Simulated clinical provides students the opportunity to use practice holistic nursing in a safe environment. A simulated clinical experience for a first semester student may focus on the introduction of two variables such as a physiological variable and a spiritual variable while a second semester scenario could incorporate three or more variables. Holistic nursing variables can be taught using high or moderate-fidelity mannequins or standardized patients depending on the scenario objectives.

High-fidelity mannequins are best for scenarios designed for teaching holistic care of patients with physiological variables because human physiologic functions can be programmed and trended. A high-fidelity mannequin is best for scenarios that combine physiological with other variables such as psychological. For example a scenario designed to teach students holistic care of a patient experiencing anxiety would involve programming the mannequin for changes in heart rate, blood pressure, respiratory rate as the patient becomes anxious. The mannequin vocalizations would reflect patient anxiety. A standardized patient is useful for teaching health management variables that require teaching the patient psychomotor skills such as insulin administration.

A realistic environment is important for simulated clinical experiences. Specific equipment and props are needed to meet specific scenario outcomes. The following equipment is suggested for meeting the outcomes presented in this scenario. A patient room and a control room with advanced audio/video recording. This is necessary for the debriefing. If a two-room set up is not possible, the computer and facilitator should be not be in the student's view during the scenario. The presence of the facilitator can be distracting for the student(s). A camera connected to the computer should be set up to capture the clinical simulation. An in-patient room with hand hygiene equipment, a hospital bed, a nurse call bell, an over bed table, a chair, a water pitcher, a cup and a phone is necessary for safety and infection control. Books, magazines, artificial flowers, get-well cards, photos, tissues, a cane and Rosary beads that can be placed on the simulator's hand or on the over bed table are necessary for basic care and comfort. An electronic health record or paper chart with orders including a medication administration record as well as a PYXIS ${ }^{\circledR}$ or medication cart with ordered medications is necessary for pharmacological therapy are necessary for reduction of risk potential.

A high-fidelity mannequin or standardized patient dressed as a female patient (for a female facilitator) or male patient (for a male facilitator) is necessary for providing holistic care. The mannequin or standardized patient may be sitting in bed or in a chair. If a high-fidelity mannequin is not available a moderate-fidelity mannequin with vital sign and voice capability can be used this is necessary for reduction of risk potential, therapeutic communication, and illness management. If the scenario does not involve any changes in vital signs, a standardized patient can be used. A performing arts student may be interested in this role. If this is the case, the nursing student(s) can assess the standardized patient's vital signs using equipment designed for humans and simulate medication administration as they would for the high or moderate fidelity mannequin that does not actually swallow the medication or drink the water. Standardized patients must be briefed on the scenario objectives and the unfolding of the scenario.

\section{I mplications for nursing education}

Both the ANA and AACN call for nurses to use a holistic framework when caring for patients. Providing nurses with the knowledge, attitude, and skills necessary for providing holistic care can be challenging. Clinical simulation provides students the opportunity to learn holistic nursing practice. For the past five years one on one student/facilitator simulated clinical experiences have been used at our University to teach holistic nursing processes. Holistic processes are introduced during the fall junior year semester and are expanded upon during the entire educational experience. Multiple years of 
student evaluations have been useful for examining and understanding student experiences and learning with clinical simulation. Overall students perceive clinical simulations as realistic and important for learning. They feel clinical simulation fosters self-evaluation of nursing care.

One on one student/facilitator experiences are resource-intensive. Multiple instructors with clinical simulation knowledge are needed. It may be difficult to schedule one on one simulations in programs with a large number of students. As stated earlier clinical simulations can be conducted with small groups. If small groups of 4-6 students are used, a specific role for each student should be assigned prior to the simulation experience. If the experience is graded, a group grading rubric would be needed. The facilitator must provide guidance through prompting for each participant. This article presents one strategy for teaching healing principles however, multiple learning activities are necessary for incorporating healing principles into individual nursing practice. The principles must be introduced and reinforced in the classroom, laboratory and clinical practice. Faculty should serve as role models and support students as they learn holistic nursing practice.

\section{References}

[1] American Nurses Association. Scope and standards of practice. Silver Spring: American Nurses Association. $2010: 23$.

[2] American Association of Colleges of Nursing. Recommended baccalaureate competencies and curricular guidelines for the nursing care of older adults. 2010: 8. Retrieved from AACN website: www.aacn.nche.edu

[3] American Holistic Nurses Association. Holistic nursing: Scope and standards of practice. Silver Spring: American Holistic Nurses Association, American Nurses Association. 2010:1.

[4] Barrere C. Teaching future holistic nurses: integrating holism into an undergraduate nursing curriculum. In Holistic Nursing: A handbook for practice. B Dossey \& L Keegan, eds. Boston: Jones and Bartlett; 2009: 709-717.

[5] Herrmann E. Mrs. Chase a noble and enduring figure. The American Journal of Nursing. 1981; $10: 1836$. http://dx.doi.org/10.1097/00000446-198110000-00030

[6] Solnick A, Weiss S. High fidelity simulation in nursing education: A review of the literature. Clinical Simulation in Nursing Education. 2007; 3: e41-e45. http://dx.doi.org/10.1016/j.ecns.2009.05.039

[7] Strand I, Naden D, Slettebo A. Students learning in a skills laboratory. Nursing Science. 2009; 29(3): 18-22.

[8] Whitmire V, Utz S. Teaching the art of holistic nursing. Journal of Holistic Nursing. 1986; 4(1): 27-30. PMid:3638331 http://dx.doi.org/10.1177/089801018600400108

[9] Blum C, Hickman C, Parcells D, Locsin R. Teaching caring nursing to RN-BSN students using simulation technology. International Journal for Human Caring. 2010; 14 (2).

[10] Hoke M, Robbins L. The impact of active learning on nursing students’ clinical success. Journal of Holistic Nursing. 2005; 23(3): 348-355. PMid:16049122 http://dx.doi.org/10.1177/0898010105277648

[11] Adler P. Teaching massage to nursing students of geriatrics through active learning. Journal of Holistic Nursing. 2009; 27(1): 51-56. PMid:19181909 http://dx.doi.org/10.1177/0898010108329132

[12] Gasper M, Dillon P. Clinical simulation in nursing education. Philadelphia: F.A. Davis; 2012.

[13] Cambell S, Daley K. Simulation Scenarios for Nurse Educators: Making it Real. New York: Springer; 2009.

[14] Shea J. Assessing a patient with a Mood Disorder. In Simulation Scenarios for Nurse Educators: Making it Real. S Cambell \& K Daley, eds. New York: Springer; 2009: 179-190.

[15] Mariano C. Holistic Nursing: Scope and Standards of Practice. In Holistic Nursing: A Handbook for Practice. B Dossey \& L Keegan, eds. Boston: Jones and Bartlett; 2013: 59-84.

[16] Barrere C. Teaching future holistic nurses: Integration of holistic and quality and safety education for nurses (QSEN) concepts. In Holistic Nursing: A handbook for practice. B Dossey \& L Keegan, eds. Boston: Jones and Bartlett; 2013: 815-824.

[17] Dossey B, Luck S, Schaub B, \& Keegan L. In Holistic Nursing: A Handbook for Practice. B Dossey \& L Keegan, eds. Boston: Jones and Bartlett; 2013: 161-187.

[18] Jeffries P, Rogers K. Evaluating simulations. In Simulation in nursing education from conceptualization to evaluation. P Jeffries, ed. New York, NY: National League for Nursing; 2007: 87-103.

[19] (INASCL) International Nursing Association for Clinical Simulation in Nursing. Standard I: Terminology. Clinical Simulation in Nursing. 2011; 7: S3-S7. http://dx.doi.org/10.1016/j.ecns.2011.05.005

[20] Cordeau M. The lived experience of clinical simulation of novice nursing students. International Journal for Human Caring. 2010; 14 (2): 8-14. 